\title{
The regulation of adipose cell metabolism
}

\author{
By D. J. Galton and S. Wallis, Department of Medicine, St. Bartholomew's \\ Hospital, West Smithfield, London ECI
}

The adipose cell maintains a central role in the regulation of lipid metabolism (Galton, 197I). It contains the largest store of triglyceride and cholesterol in the body; it is the only source of plasma fatty acids, a major oxidative fuel, particularly in the fasting state, and it is the major site of clearance of chylomicrons and very-low-density lipoprotein (VLDL) in the fed state. The importance of the tissue for fuel metabolism is observed in conditions of generalized lipodystrophy (total atrophy of adipose tissue) where a severe hyperlipidaemia develops often with glucose intolerance (Schwartz et al. 1960).

The metabolic pathways of the cell are regulated by a variety of agents including hormones, apolipoproteins and metabolites (Fig. I). It is convenient to consider this in terms of the regulation of substrate utilization by the cell, then to consider the substrate output from the cell.

\section{Substrate utilization}

The major substrates entering the adipose cell are glucose and triglyceride-fatty acids derived from the breakdown of chylomicrons or VLDL. The removal of cholesterol-rich lipoproteins from plasma may also be an important function of adipose tissue since high-affinity LDL-receptors have been detected on the adipocyte membrane.

Glucose. The uptake of glucose by adipose tissue is probably quantitatively unimportant compared to the uptake by muscle, heart or liver. If one considers a $70 \mathrm{~kg}$ man of whom $30 \mathrm{~kg}$ may be muscle and $10 \mathrm{~kg}$ adipose tissue, then of a $100 \mathrm{~g}$ oral glucose load, only approximately $10 \mathrm{~g}$ enters adipose tissue. The entry of glucose is regulated by insulin at low plasma concentrations of glucose, but at high plasma levels intracellular phosphorylation of glucose by glycolytic enzymes may become rate-determining.

Although glucose uptake by adipose tissue is small, it may be an important regulator of an intracellular substrate cycle - the glyceride-fatty acid cycle (Galton \& Betteridge, 1977). The components of this cycle are shown in Fig. 2. The features are a continuous flux of triglyceride hydrolysis to fatty acids and then re-esterification of fatty acids with glycerol phosphate derived from glucose. The operation of the substrate cycle requires hydrolysis of ATP and is energetically wasteful. However, it provides for short-term regulation of glucose and fatty acid metabolism by the tissue. Thus, in the fed state (high plasma glucose and insulin) the left arm of the cycle is active and reduces the release of fatty acids from adipose tissue thereby conserving fatty acids. In the fasted state plasma glucose and insulin are low, the left-hand side of the cycle becomes less active and release of fatty acids 


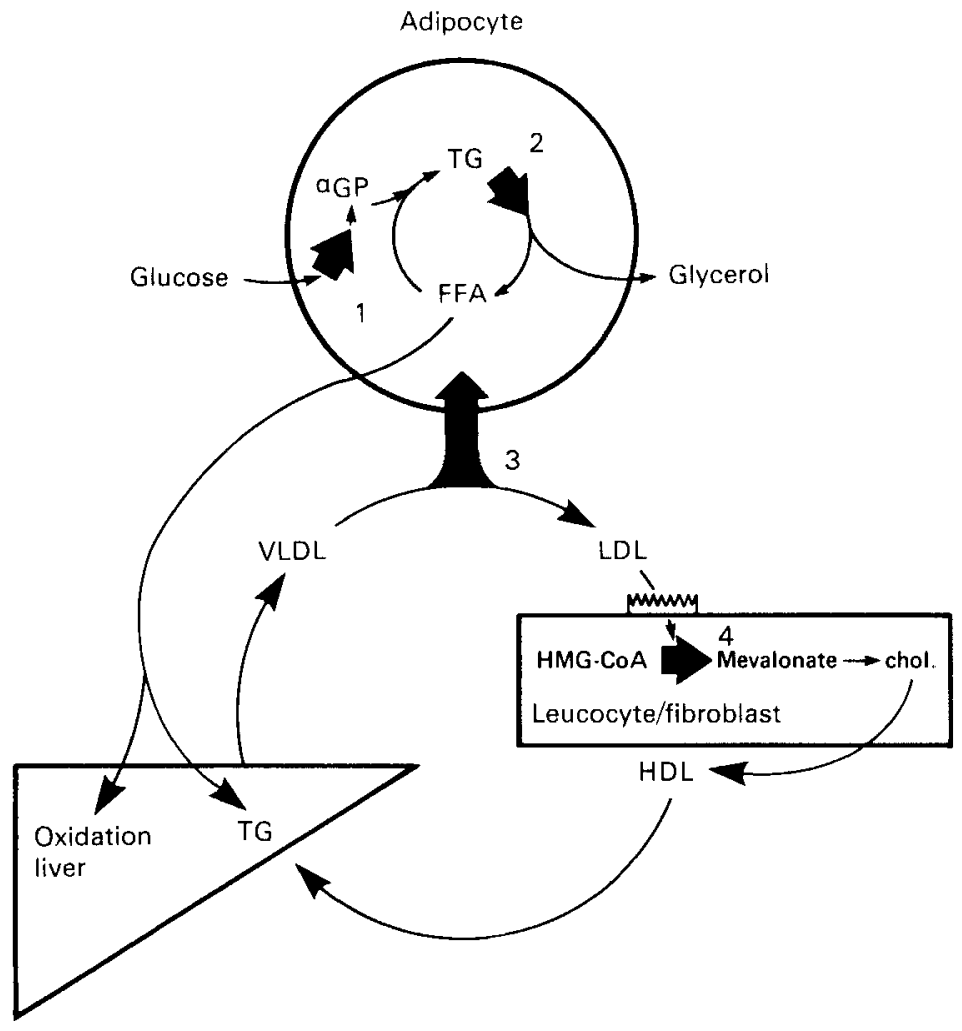

Fig. I. A schematic representation of the metabolism of lipids by adipose tissue in relation to other tissues.

TG, triglyceride; FFA, free fatty acid; VLDL, very-low-density lipoprotein; LDL, low-density lipoprotein; HDL, high-density lipoprotein; GP, glycerol phosphate.

Regulatory enzymes: (1) hexokinase-phosphofructokinase, (2) hormone-sensitive triglyceride lipase, (3) lipoprotein lipase, (4) 3-hydroxy 3-methyl glutaryl coenzyme A reductase.

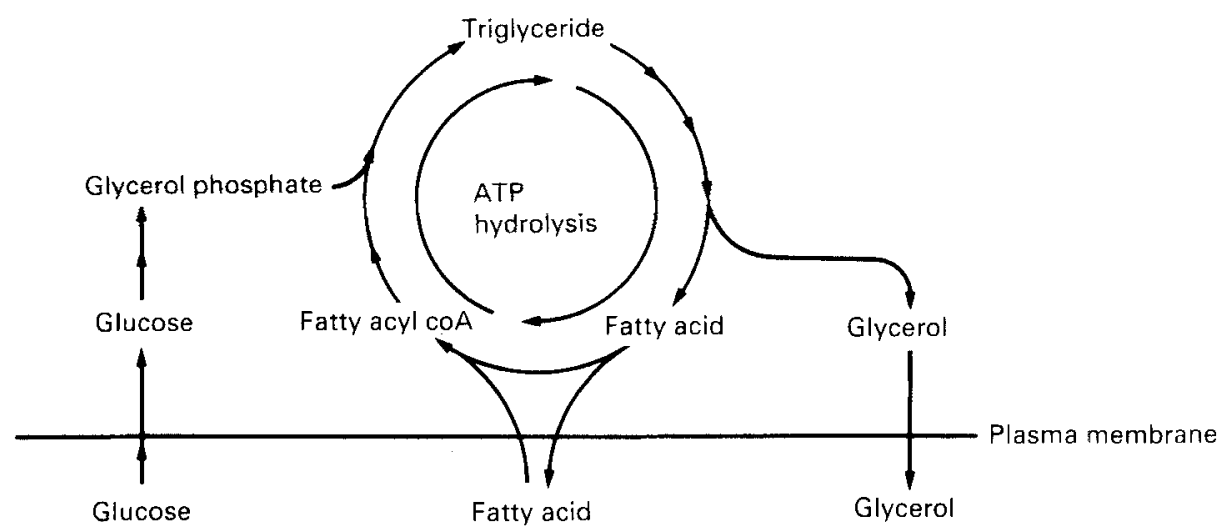

Fig. 2. The triglyceride-fatty acid substrate cycle in adipose tissue. The catabolic pathway of this cycle is lipolysis; the anabolic pathway is esterification. Not all reactions on each pathway are represented. 
from the tissue is increased. Thus, glucose and fatty acids are linked reciprocally by the activity of this substrate cycle, independently of hormonal controls, and this provides for the changes in fuel economy between fed and fasted states.

Insulin, apart from regulating the entry of glucose into cells, may also have direct effects on the regulation of intracellular enzymes involved in glucose metabolism (Denton et al. 1977). Our laboratory has been recently studying the activity of pyruvate kinase in human adipocytes (Stansbie et al. 1982). This enzyme is present in high activities and appears to be under acute regulation by insulin (Fig. 3). This may involve phosphorylation-dephosphorylation reactions converting a high $K_{m}$ to a low $K_{m}$ form of the enzyme by analogy with pyruvate kinase in the liver (Denton \& Halestrap, I979). If fasted human subjects are given intravenous infusions of glucose (and insulin) it is possible to detect changes in the $K_{m}$ of pyruvate kinase after $30 \mathrm{~min}$. The mechanism of insulin action on the interconversion of pyruvate kinase, and other key regulatory enzymes such as hexokinase and phosphofructokinase in adipose tissue requires further study and may help to clarify the cause of various insulin-resistant states occurring in adult diabetics.

Triglyceride-rich lipoproteins. Adipose tissue is the major site of uptake of chylomicrons and VLDL in the fed state (Robinson, 1970). These lipoproteins are hydrolysed in the capillary bed of the tissue by an endothelial-bound enzyme, lipoprotein lipase ( $E C$ 3.I.I.3). The activity of this enzyme changes in parallel with the capacity of adipose tissue to assimilate lipoprotein triglyceride (Taylor et al. I979). Lipoprotein lipase is synthesized and secreted by adipocytes for attachment to the capillary endothelium where hydrolysis of the core triglyceride of VLDL

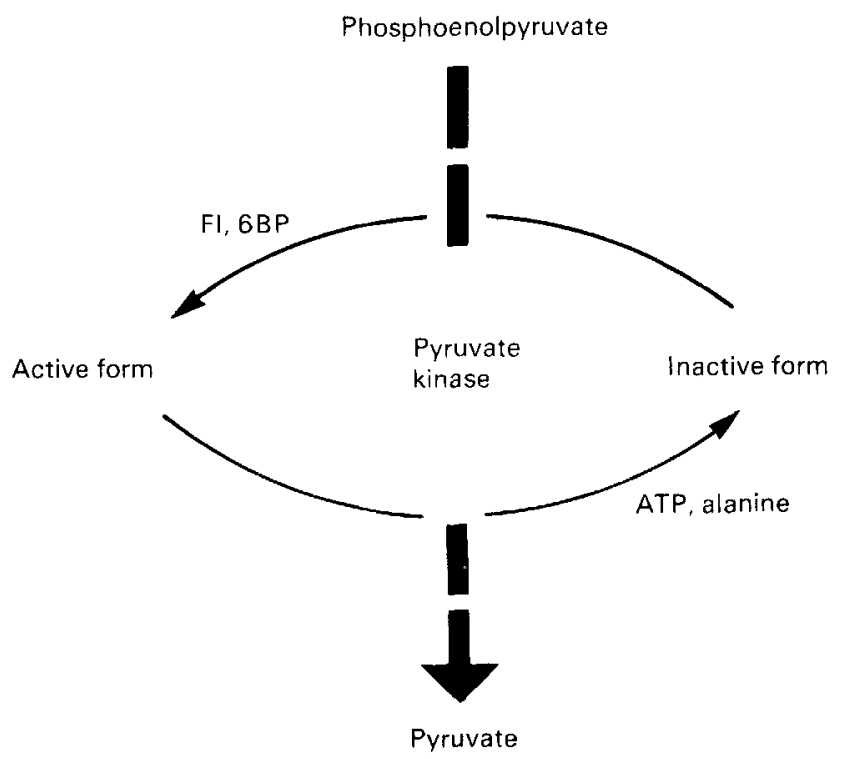

Fig. 3. Scheme for the regulation of pyruvate kinase. Insulin favours the conversion of the enzyme to the more active form. 
occurs in sequential steps. The liberated fatty acids traverse the endothelium for uptake by adipocytes. Lipoprotein lipase is under short-term regulation by surface-bound peptides carried on triglyceride-rich lipoproteins, and also under long-term regulation by hormones, primarily insulin and cortisol.

Short-term control. Apolipoprotein C-II (apo C-II) contains a single polypeptide of seventy-eight amino acids, with a molecular weight of 8837 daltons. It is an obligatory activator for lipoprotein lipase from various sources including human and rat post-heparin plasma, cow's milk and human adipose tissue. The peptide stimulates enzyme activity by ten- to twenty-fold over a concentration range of I-5 $\mu \mathrm{g} / \mathrm{ml}$. Apo C-II may be an allosteric modifier of lipoprotein lipase, although the possibility of direct facilitation of enzyme-substrate binding by the peptide has not been excluded (Schaefer $e t$ al. 1978). Several patients and kindreds have been reported with inherited or acquired deficiencies of apo C-II peptide (Breckenridge et al. 1978; Reckless et al. 1979). They survive well into middle-age and present with a phenotype resembling a type $\mathrm{V}$ hyperlipidaemia. Lipoprotein lipase activities in adipose tissue are normal, but the enzyme cannot be stimulated by VLDL derived from the patient, although it can be stimulated by control VLDL. Infusion of apo C-II peptide into such patients (as fresh frozen plasma) reverses the hyperlipidaemia for a short time.

Apolipoprotein C-III (apo C-III) is the most abundant of the apo C-proteins in triglyceride rich lipoproteins. It is a seventy-nine residue polypeptide (molecular weight 8764 daltons) occurring in three isomorphic forms depending on the number of sialic residues attached to threonine-74 (Rifkind \& Levy, 1977). The sialylated forms of this peptide (apo C-III-2) may interfere with enzyme-substrate binding and impair lipoprotein catabolism. Thus several patients have been observed with severe hypertriglyceridaemia whose triglyceride-rich lipoproteins contain an excessive amount of apo C-III-2 (Stocks et al. 1979). Although this lipoprotein activates lipoprotein lipase, normally it acts as a less efficient substrate for the enzyme in vitro. Limited incubation of the variant lipoprotein with neuraminidase caused a partial loss of sialic acid from the apo C-III-2 peptides and resulted in a triglyceride-rich lipoprotein displaying normal substrate interaction with lipoprotein lipase. The extent of sialylation of the apo C-III peptides carried on triglyceride-rich lipoproteins may be critical for their interaction with lipoprotein lipase and affect the clearance rate from plasma (Holdsworth et al. I982).

Long-term control. The long-term regulation of lipoprotein lipase involves induction/repression mechanisms by insulin and possibly other hormones such as cortisol. When adipose tissue or $3 \mathrm{~T}_{3}$ adipocytes (an adipocyte precursor) is incubated with insulin there is a dose-dependent rise in activity of lipoprotein lipase which can be blocked by transcriptional inhibitors such as actinomycin D or $\alpha$-amanitine; or enzyme production can be impaired by translational inhibitors such as cycloheximide or puromycin (Spooner et al. 1979). In clinical states associated with severe insulin deficiency, such as insulin-deficient diabetes very low activities of lipoprotein lipase are detectable in human adipose tissue and the 
patients are often hypertriglyceridaemic. Administration of insulin increases the activity of lipoprotein lipase in adipose tissue of insulin-resistant diabetics and there is a concurrent fall in levels of plasma triglycerides (Taylor et al. 1979). It is also possible that the insulin deficiency in starvation is responsible for the diversion of lipoprotein-triglyceride away from adipose tissue, due to a fall in activity of lipoprotein lipase. Other tissues, such as muscle, become more important sites for the uptake of plasma triglycerides, and then use glyceride-fatty acids as a major oxidative fuel.

Cholesterol rich lipoproteins. It has recently become apparent that adipose tissue may be an important site for LDL uptake from the blood stream. The tissue contains a large store of cholesterol, and since rates of sterol synthesis are small the source may derive from circulating LDL. Isolated human adipose cells contain a high-affinity receptor which can bind to LDL and stimulate endocytosis by the cell degrading the LDL to free cholesterol (for storage) and amino acids (Angel et al. 1979). Furthermore, if swine LDL is tagged with $\left[{ }^{14} \mathrm{C}\right]$ sucrose and injected intravenously into normal pigs the differential organ content for ${ }^{14} \mathrm{C}$ can be analysed at 24 or $48 \mathrm{~h}$, to determine the major sites of uptake. About $35 \%$ of LDL catabolism can be accounted for by extrahepatic tissues of which adipose tissue accounts for about $20 \%$, muscle $12 \%$, lung II $\%$, small intestine $25 \%$ and skin $9 \%$ (Steinberg et al. 1980). Since the entry of LDL into adipose tissue is mediated by a high-affinity receptor, perhaps analogous to the fibroblast receptor, regulation at this level may play an important role in LDL homoeostasis if approximately $20 \%$ of LDL is degraded by the adipose organ.

\section{Substrate efflux}

Fatty acids and glycerol. Lipolysis is the major pathway for the release of glycerol and fatty acids from adipose tissue. The basic components of this pathway are shown in Fig. 4. Triglyceride lipase is the rate determining enzyme under control by an enzyme cascade involving adenylate cyclase, phosphodiesterase and a protein kinase. The enzyme cascade is regulated by a variety of hormones of which catecholamines have been the most studied. Beta-adrenergic receptors on the cell membrane stimulate adenylate cyclase to produce cyclic AMP which subsequently activates the enzyme cascade with the eventual breakdown of intracellular triglyceride to glycerol and free fatty acids.

The pathway can be inhibited by various metabolite and hormonal signals, of which probably the most important are prostaglandins (directly inhibiting adenylate cyclase), adenosine and insulin (whose mechanism of action remains obscure). Since prostaglandins can be synthesized from arachidonic acid released by the action of triglyceride lipase, this may represent an example of end-product inhibition of the pathway.

Several defects have been identified in the adrenergic mechanisms regulating lipolysis (Galton et al. 1976; Enzi et al. 1977). They give rise to abnormal storage of triglyceride in various regions of the body. We have reported a study of two children with abnormal deposits of adipose tissue. In both subjects, adipocytes 


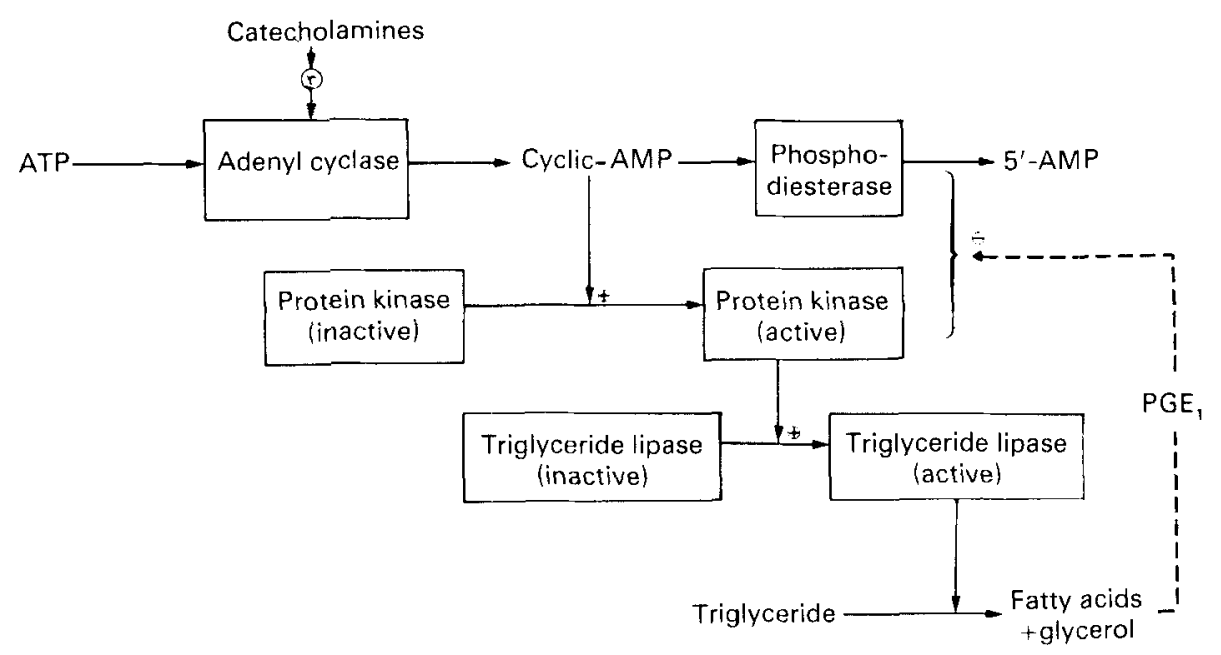

Fig. 4. The lipolytic pathway in adipose tissue. For details, see p. I 71.

were resistant to the lipolytic action of isoprenaline $\left(\mathrm{IO}^{-5} \mathrm{M}\right)$ (Galton et al. 1977). A similar abnormality of adrenergic-resistant adipocytes has been described by Enzi et al. (1977) in a group of ten adult subjects with abnormal deposits of adipose tissue around the neck and trunk. The abnormal adipocytes showed a complete lack of lipolytic response to catecholamines although they were still sensitive to dibutyryl cyclic AMP and theophylline. The results of Enzi et al. (1977) suggest that a metabolic defect located at a level preceding the formation of cyclic-AMP may be responsible for the lipolytic defect in these subjects.

\section{Conclusions}

The adipose cell is the major fuel cell of the body. The major metabolic pathways are lipogenesis from glucose and fatty acids derived from triglyceride-rich lipoproteins and lipolysis of storage triglyceride to fatty acids and glycerol. Glucose uptake for lipogenesis is regulated by insulin; and lipoprotein lipase for triglyceride-fatty acid uptake is regulated by insulin and by surface-bound peptides on lipoproteins (apo C-II, apo C-III). The tissue mobilizes stored triglyceride as fatty acids and glycerol and this pathway is regulated by catecholamines. Insulin, prostaglandins and other metabolites (e.g. adenosine) may be inhibitory to the pathway. Three basic abnormalities of substrate flow can occur in adipose tissue. Defects occur in the adrenergic mechanisms regulating lipolysis to produce abnormal tissue storage of triglyceride. Defects occur in the VLDL pathway either at the regulation or activity of lipoprotein lipase contributing to some types of hypertriglyceridaemia. Finally the tissue can become resistant to the action of insulin regulating glucose transport or intracellular enzymic activities and these may be important determinants for the pathogenesis of adult diabetes. 
Financial support from the British Diabetic Association and Medical Research Council is gratefully acknowledged.

\section{REFERENCES}

Angel, A., D'Costa, M. A. \& Yuen, R. (1979). Can. F. Biochem. 57, $57^{8}$.

Breckenridge, W. C., Little, A., Steiner, G., Chow, A. \& Poapst, M. (1978). New Engl. f. Med. 298, 1265 .

Denton, R. M., Bridges, B., Brownsey, R., Evans, G., Hughes, W. \& Stansbie, D. (1977). Biochem. Soc. Trans. 5, 894 .

Denton, R. M. \& Halestrap, A. M. (1979). Essays in Biochemistry 15, 37.

Enzi, G., Inelin, E. M., Bartissio, A., Dorigo, P., Prosdocine, M. \& Mazzoleni, F. (1977). F. clin. Invest. 60, $122 \mathrm{I}$.

Galton, D. J. (1971). The Human Adipose Cell: Model for Errors in Metabolic Regulation. London: Butterworths.

Galton, D. J. \& Betteridge, D. J. (1977). Mol. Aspects Med. i, 367 .

Galton, D. J., Gilbert, C., Lucey, J. J. \& Walker-Smith, J. A. (1977). Paediatrics 59, 442.

Galton, D. J., Reckless, J. P. D. \& Taitz, L. (1976). Acta Paediat. Scand. 65, 761.

Holdsworth, G., Stocks, J., Dodson, P. M. \& Galton, D. J. (I982). F. clin. Invest. (In the Press).

Reckless, J. P. D., Stocks, J., Holdsworth, G., Galton, D. J., Suggett, A. J. \& Walton, K. W. (1979). Clin. Sci. 57, ${ }_{3} \mathrm{P}$.

Rifkind, B. M. \& Levy, R. I. (1977). In Hyperlipidaemia: Diagnosis and Therapy New York: Grune \& Stratton.

Robinson, D. S. (1970). In Comprehensive Biochemistry, vol. I8 [M. Florkin and E. H. Stotz, editors]. Amsterdam: Elsevier.

Schaefer, E. J., Eisenberg, S. \& Levy, R. I. (1978). 7. Lipid Res. 19, 667.

Schwartz, R., Schafer, I. \& Renold, A. E. (1960). Am. F. Med. 28, 973 .

Spooner, P. M., Chernick, S. S., Garrison, M. M. \& Scow, R. O. (1979). f. biol. Chem. 254, 1002 I.

Stansbie, D., Dawson, A., Denton, R. M., Galton, D. J. \& Samian, M. R. (1982). Diabetologia (In the Press).

Steinberg, D., Pittman, R. C., Attie, A. D., Carew, T. E., Pangbam, S. \& Weinstein, D. (I980). Atherosclerosis $\mathrm{V}, 800$.

Stocks, J., Holdsworth, G. \& Galton, D. J. (1979). Lancet ii, 667.

Taylor, K. G., Galton, D. J. \& Holdsworth, G. (1979). Diabetologia 16, 3 × 3. 